\title{
Leçon d'histoire
}

\author{
Maryse Condé
}

S ouvent, après le dîner qu'Adelia servait à sept heures du soir tapantes, mon père et ma mère se prenaient par le bras et sortaient prendre la fraîcheur. Ils descendaient notre rue jusqu'à la somptueuse maison entre cour et jardin des Lévêque, des blancs pays qu'on voyait à la grand messe, le père, la mère, cinq enfants et une tante demoiselle montée en graine sous sa mantille, mais qui le reste du temps, semblaient vivre derrière rideaux baissés et portes closes. Ils tournaient à gauche et en passant devant le cinéma-théâtre La Renaissance, ils jetaient un coup d'oeil de mépris aux affiches des premiers films américains en technicolor. Ils haïssaient l'Amérique sans y avoir jamais mis les pieds parce qu'on y parlait anglais et parce que ce n'était pas la France. Ils faisaient le tour de la Darse humant la brise qui venait de la mer, poussaient jusqu'au quai Ferdinand de Lesseps où une odeur de morue salée s'accrochait toujours aux branches basses des amandiers - pays, revenaient vers la place de la Victoire et après avoir monté et descendu trois fois l'allée des Veuves, ils s'aseyaient sur un banc. Ils demeuraient là jusqu'à neuf heures et demie. Puis, se levaient avec ensemble et rentraient à la maison par le même chemin tortueux.

Ils me traînaient toujours derrière eux. Parce que ma mère était toute fière d'avoir une si jeune enfant dans son âge plus que mûr et aussi parce qu'elle n'était jamais en paix lorsque j'étais loin d'elle. Moi, je ne prenais aucun plaisir dans ces promenades. J'aurai bien préféré rester à la maison avec mes frères et soeurs. Sitôt que mes parents leur avaient donné dos, ils commençaient de chahuter. Mes frères s'entretenaient avec leurs gamines sur le pas de la porte. Ils mettaient des disques de biguine sur le phonographe, se racontaient toutes espèces de blagues en créole. Sous le prétexte qu'une personne bien élévée ne mange pas dans la rue, au cours de ces sorties, mes parents ne m'achetaient ni pistaches bien grillées, ni sukakoko. J'en étais réduite à convoiter toutes ces douceurs et à me poster devant les marchandes dans l'espoir que malgré mes vêtements achetés à Paris, elles me prendraient en pitié. Des fois, la ruse marchait et l'une d'entre elles, la figure à moitié éclairée par son quinquet, me tendait une main pleine:

— Tiens pour toi! Pitit à manman! 
En plus, mes parents qui étaient rarement seuls, ne s'occupaient guère de moi et parlaient entre eux. De Sandrino qu'on avait encore menacé de renvoyer du Lycée. D'une de mes soeurs qui n'étudiait pas à l'école. D'investissements financiers, car mon père était un excellent gestionnaire. Encore et toujours de la méchanceté du coeur des gens de La Pointe qui n'en revenaient pas que des nègres réussissent leur vie comme ils réussissaient la leur. À cause de cette paranoïa de mes parents, j'ai vécu mon enfance dans l'angoisse. J'aurai tout donné pour être l'enfant de gens ordinaires, anonymes. J'avais l'impression que les membres de ma famille étaient menacés, exposés à proximité du cratère d'un volcan dont la lave en feu risquait à tous les instants de les consumer. Je masquais ce sentiment tant bien que mal par des affabulations et une agitation constantes, mais il me rongeait.

Mes parents s'asseyaient toujours sur le même banc, contre le kiosque à musique. S'il était occupé par des indésirables, ma mère restait planté devant eux, battant la mesure du pied, avec une mine tellement impatiente qu'ils ne tardaient pas à déguerpir. Seule, je m'amusais comme je pouvais. Je sautais à cloche-pied dans les allées. Je shootais des cailloux. J'écartais les bras et je devenais un avion qui vole dans l'air. J'interpellais les étoiles et le croissant de lune dans le ciel. À haute voix, avec de grands gestes, je me racontais des histoires. Un soir que je $\mathrm{m}$ 'amusais à ma manière solitaire, une petite fille surgit de la noirceur. Blondinette, mal fagotée, une queue de cheval fadasse dans le dos. Elle m'apostopha en créole:

- Ki non a-w?

Je me demandai en mon for intérieur pour qui elle me prenait. Pour l'enfant de riens-dutiut? Espérant faire mon petit effet, je déclinai mon identité avec emphase. Elle ne sembla pas ébranlée, car il était visible qu'elle entendait mon patronyme pour la première fois et poursuivit avec la même autorité, toujours en créole:

— Moi, c'est Anne-Marie de Surville. On va jouer! Mais attention, ma maman ne doit pas voir que je $m$ 'amuse avec toi sinon, elle me battrait.

Je suivis son regard et $j$ 'aperçus quelques femmes blanches immobiles, assises de dos, les cheveux flottant uniformément sur les épaules. Les façons de cette Anne-Marie ne me plaisaient pas du tout. Un moment, je fus tenté de tourner les talons et rejoindre mes parents. En même temps, $\mathrm{j}$ 'étais trop heureuse de trouver une partenaire de mon âge même si elle me commandait comme à sa servante.

Immédiatement, Anne-Marie prit la direction de nos jeux et toute la soirée, je me soumis à ses caprices. Je fus la mauvaise élève et elle me tira les cheveux. En plus, elle releva ma robe pour m'administrer la fessée. Je fus le cheval. Elle monta sur mon dos et elle me bourra les 
côtes avec des coups de pied. Je fus la bonne et elle me souffleta. Tout le temps, elle $\mathrm{m}$ 'abreuvait de gros mots. Je frémissais en entendant voler les kouni à manman a-w et les tonnè dso interdits. Finalement, une ultime taloche me fit tellement mal que je courus retrouver les bras de ma mère. Dans ma honte, je ne m'expliquais pas. Je prétextai que $j$ 'avais pris un saut et laissai mon bourreau continuer de gambarder en toute impunité près du kiosque à musique. Le lendemain, Anne-Marie m'attendait au même endroit. Pendant plus d'une semaine, elle fut fidèle au poste et je me livrai sans protester à ses services. Après qu'elle eut manqué m'éborgner, je finis par protester, lassée de sa brutalité:

- Je ne veux plus que tu me donnes des coups.

Elle ricana et m'allongea une vicieuse bourrade au creux de l'estomac:

- Je dois te donner des coups parce que tu es une négresse.

Je trouvais la force de m'éloigner d'elle.

Sur le chemin du retour à la maison, j'eus beau méditer sa réponse, je ne lui trouvai ni rime ni raison. Au moment du coucher, après les prières aux divers anges gardiens et à tous les saints $\mathrm{du}$ paradis, $\mathrm{j}$ 'interrogeai ma mère:

— Pourquoi doit-on donner des coups à des nègres?

Ma mère sembla d'abord estomaquée, puis elle s'exclama:

— Comment une petite fille aussi intelligente que toi peut-elle poser pareilles questions?

Ensuite, elle traça en vitesse un signe de croix sur mon front, se leva et se retira en éteignant la lumière de ma chambre. Le lendemain matin, à l'heure de la coiffure, je revins à la charge. Je sentais que la réponse à ma question fournirait la clé à l'édifice souvent mystérieux de mon monde. La vérité sortirait de la jarre où on la tenait enfermée. Devant mon insistance, ma mère me frappa sèchement avec le dos du peigne:

- Enfin, cesse de raconter des bêtises. Est-ce que tu vois quelqu'un donner des coups à ton papa

ou à moi?

La suggestion était invraisemblable. Pourtant, la fébrilité de ma mère trahissait son embarras. Elle me cachait quelque chose. À midi, j'allai rôder dans la cuisine autour des jupes d'Adélia. Hélas! Elle faisait tourner une sauce. Aussitôt qu'elle maperçut, avant seulement 